\title{
Impact of atrial fibrillation on clinical outcomes among patients with coronary artery disease undergoing revascularisation with drug-eluting stents
}

Thomas Pilgrim¹, MD; Bindu Kalesan ${ }^{1,4}$, MPH; Thomas Zanchin ${ }^{1}$, BA; Cédric Pulver ${ }^{1}$, BA; Simon Jung 2 , MD; Heinrich Mattle², MD; Thierry Carrel², MD; Aris Moschovitis ${ }^{1}$, MD; Stefan Stortecky ${ }^{1}$, MD;

Peter Wenaweser ${ }^{1}$, MD; Giulio G. Stefanini ${ }^{1}$, MD; Lorenz Räber ${ }^{1}$, MD; Bernhard Meierr ${ }^{1}$, MD; Peter Jüni ${ }^{4}$, MD; Stephan Windecker ${ }^{*}$, MD

1. Department of Cardiology, Bern University Hospital, Bern, Switzerland; 2. Department of Neurology, Bern University Hospital, Bern, Switzerland; 3. Department of Cardiovascular Surgery, Bern University Hospital, Bern, Switzerland; 4. Institute of Social and Preventive Medicine and Clinical Trials Unit, Bern University Hospital, Bern, Switzerland

T. Pilgrim and B. Kalesan contributed equally to this work.

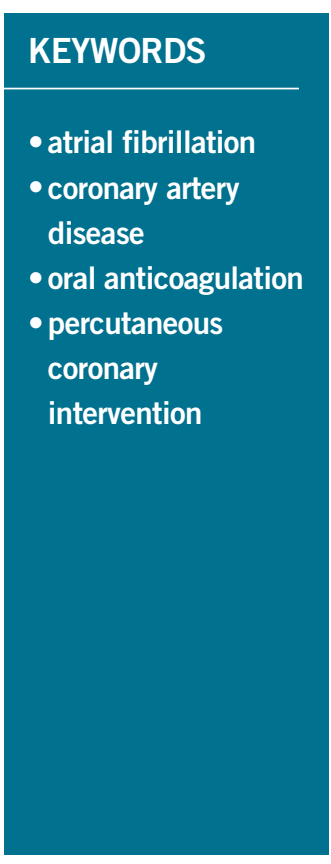

\begin{abstract}
Aims: Coronary artery disease (CAD) and atrial fibrillation (AF) are major determinants of morbidity and mortality. A combined treatment with antiplatelet agents and vitamin $\mathrm{K}$ antagonists limits the risk of stent thrombosis and stroke while increasing the rate of bleeding. The objective of this study was to investigate the impact of atrial fibrillation (AF) on long-term clinical outcomes in patients with CAD undergoing percutaneous coronary intervention (PCI) with drug-eluting stents (DES).
\end{abstract}

Methods and results: Among 6,308 consecutive patients undergoing PCI with DES between 2002 and 2009, 323 (5.3\%) patients were diagnosed with AF. We compared clinical outcomes between patients with and those without AF throughout four years. The primary endpoint was a composite of all-cause mortality, myocardial infarction (MI), ischaemic stroke, and BARC bleeding type $3 \mathrm{~b} / 3 \mathrm{c} / 5 \mathrm{a} / 5 \mathrm{~b}$. In adjusted analyses, the primary composite endpoint was more frequent among patients with $\mathrm{AF}$ (HR 1.59, 95\% CI 1.26-2.00; $\mathrm{p}<0.001$ ). Differences were driven by an increased risk of all-cause mortality (HR 1.67, 95\% CI 1.27-2.20; $\mathrm{p}=0.003$ ), ischaemic stroke (HR 3.09, 95\% CI 1.45-6.56; $\mathrm{p}=0.003$ ), and intracranial bleeding (HR 4.28, 95\% CI 1.36-13.48; $\mathrm{p}=0.013$ ). We observed a gradient of risk among patients with higher $\mathrm{CHA}_{2} \mathrm{DS}_{2}$-VASc scores and modified outpatient bleeding risk index.

Conclusions: Among patients with CAD undergoing revascularisation with DES, AF confers an increased risk of all-cause mortality, ischaemic stroke, and intracranial bleeding. The hazard imposed by AF correlates with the $\mathrm{CHA}_{2} \mathrm{DS}_{2}$-VASc score.

*Corresponding author: Department of Cardiology, Swiss Cardiovascular Center Bern, Bern University Hospital, 3010 Bern, 


\section{Introduction}

Coronary artery disease (CAD) remains the leading cause of mortality in industrialised countries, while atrial fibrillation (AF) is a major risk factor for cerebrovascular accidents ${ }^{1}$ and is associated with a two to threefold increased risk of stroke among patients with CAD or heart failure ${ }^{1}$. CAD and AF coexist in up to $25 \%$ of patients with stable $\mathrm{CAD}$ or acute myocardial infarction $(\mathrm{MI})^{2-7}$, which may be related to common risk factors including advanced age, diabetes, hypertension, and congestive heart failure ${ }^{8,9}$. Apart from cerebrovascular events, $\mathrm{AF}$ has been associated with a one-and-a-half to twofold increased risk of mortality in the general population after adjustment for pre-existing cardiovascular conditions ${ }^{8}$ as well as adverse in-hospital and long-term outcome after $\mathrm{MI}^{4,10}$.

Effective treatments of both $\mathrm{AF}$ and $\mathrm{CAD}$ have major prognostic implications for event-free survival in contemporary clinical practice. Vitamin K antagonists (VKA) reduce the risk of cerebrovascular events among patients with $\mathrm{AF}^{11}$. Similarly, percutaneous coronary interventions (PCI) reduce the risk of death and $\mathrm{MI}$ among patients with acute coronary syndromes while improving symptoms and quality of life among patients with stable $\mathrm{CAD}^{12}$. Dual antiplatelet therapy (DAPT) minimises the risk of stent thrombosis (ST) following implantation of stents and has become a mainstay in contemporary PCI practice. While the combination of antiplatelet agents with VKA aims to prevent thromboembolic events related to $\mathrm{AF}$ as well as ST, this therapeutic strategy imposes an increased risk of bleeding and malcompliance ${ }^{13}$. European and North American consensus documents provide a comprehensive review of clinical data investigating the delicate balance between stroke prevention, stent thrombosis and bleeding among patients with $\mathrm{AF}$ undergoing PCI. Since prospective clinical data are, however, limited, consensus documents are based substantially upon expert opinion and emphasise the need for further investigation ${ }^{14-16}$. Although drugeluting stents (DES) have considerably reduced the risk of repeat revascularisation compared with bare metal stents, this benefit comes at the expense of a prolonged duration of DAPT and triple antithrombotic therapy in case of concomitant $\mathrm{AF}^{17}$. Despite the introduction of bleeding risk scores ${ }^{18}$, the balance between the risk of stroke on the one hand and haemorrhagic events on the other is based largely on clinical judgement, and little is known regarding the impact of AF on ischaemic and haemorrhagic outcomes among patients undergoing PCI with DES. The objective of the present analysis was therefore to assess the impact of $\mathrm{AF}$ among patients with $\mathrm{CAD}$ undergoing PCI with the unrestricted use of DES in routine clinical practice during long-term clinical follow-up through four years.

\section{Methods}

\section{PATIENT POPULATION}

All patients undergoing implantation of DES at Bern University Hospital, Switzerland, were prospectively entered into a dedicated database. Between April 2002 and March 2009, a total of 6,535 consecutive patients underwent PCI with the unrestricted use of early and newer-generation DES. Drug-eluting stents were used in more than $90 \%$ during the study period. Considering the registry character of the study, no formal exclusion criteria applied. Demographic and clinical characteristics, information on PCI, and hospital outcome data were systematically collected. The study was approved by the institutional ethics committee at Bern University Hospital, Switzerland, and complied with the Declaration of Helsinki. Written informed consent for prospective follow-up was obtained from all patients.

\section{PROCEDURES}

It was generally recommended that oral anticoagulation be discontinued in patients undergoing elective coronary angiography three days prior to intervention with an intended target INR $<2$ at the time of the procedure. In patients with acute coronary syndromes, percutaneous coronary intervention was performed without prior discontinuation of oral anticoagulation. Patients were loaded with a thienopyridine, and anticoagulation during the intervention was guided by measurement of activated clotting time (ACT). A radial access was chosen if the bleeding risk appeared excessive due to elevated INR values. Unfractionated heparin in a dose of 5,000 IU or $70-100 \mathrm{IU} / \mathrm{kg}$ was administered during the procedure to maintain an ACT $>250$ seconds. PCI was performed in accordance with current guidelines. The antiplatelet and antithrombotic regimen was installed upon the discretion of the operator. A 12-lead electrocardiogram was routinely obtained before and after the procedure and cardiac enzymes were assessed within 24 hours of the procedure. Creatinin kinase (CK), CK-MB and troponin T were repeated every six to eight hours until identification of the peak levels in patients with signs of ischaemia.

\section{DATA COLLECTION}

AF was not formally classified at baseline. All medical records of patients with $\mathrm{AF}$ at baseline were therefore evaluated by three investigators (TP, TZ, CP), including a systematic review of all electrocardiograms at the time of admission, during the hospitalisation and at discharge. Reasons for VKA other than AF (mechanic valve prosthesis, pulmonary embolism, venous thromboembolism, pulmonary hypertension $[>50 \mathrm{mmHg}]$, left ventricular ejection fraction $<30 \%$, left ventricular aneurysm or thrombus) were also recorded. All patients were actively followed up to ascertain major adverse cerebrovascular and cardiovascular events. Survival data for all patients were obtained from hospital records and municipal civil registries. A health questionnaire was sent to all living patients with questions on rehospitalisation and major adverse cardiac events $^{19}$. In case of missing response, patients were contacted by telephone. General practitioners, referring cardiologists and patients were contacted as necessary for additional information. For patients who underwent treatment for major adverse cardiac events at other medical institutions, external medical records, discharge letters and coronary angiography documentation were systematically collected and reviewed. All major adverse cardiac events and bleeding events were adjudicated by a cardiologist, and all neurologic events by a neurologist. 


\section{DEFINITIONS}

AF was defined as at least one ECG documented episode of irregularly irregular RR intervals consistent with AF any time before discharge. Patients with atrial flutter were also included in the analysis. $\mathrm{CHADS}_{2}$ scores and $\mathrm{CHA}_{2} \mathrm{DS}_{2}$-VASc scores were created for patients with AF by the addition of points assigned to individual risk factors for stroke. Congestive heart failure, history of hypertension, age $\geq 75$ years, and diabetes contributed one point each to the $\mathrm{CHADS}_{2}$ score, whereas two points were added for previous cerebrovascular events ${ }^{20}$. The $\mathrm{CHA}_{2} \mathrm{DS}_{2}$-VASc score assigned one point each for congestive heart failure, hypertension, age 65-74 years, diabetes, vascular disease, and female gender, and two points for age $\geq 75$ years and a history of previous cerebrovascular events, respectively ${ }^{21}$.

Bleeding risk was assessed using the modified Outpatients Bleeding Risk Index (mOBRI) which takes into account age $\geq 65$ years, a history of stroke, a history of gastrointestinal bleeding, recent myocardial infarction, anaemia, renal insufficiency, and diabetes. Patients with none of the factors are assumed to have a low risk of bleeding, patients with one to two factors have an intermediate risk of bleeding, and patients with three to four factors are expected to have a high risk of bleeding ${ }^{22,23}$. We prespecified a composite primary endpoint consisting of all-cause mortality, non-fatal MI, ischaemic stroke, and BARC (Bleeding Academic Research Consortium) bleeding type 3b, 3c, and type $5 \mathrm{a}$ and $5 \mathrm{~b}$. Cardiac death was classified as death secondary to an immediate cardiac cause, procedure-related mortality, and death of unknown cause. MI was classified as Q-wave or non-Q-wave MI. Q-wave myocardial infarction was diagnosed in the circumstance of symptoms or signs of ischaemia in the presence of new pathological Q-waves in $\geq 2$ contiguous leads. Non-Q-wave myocardial infarction was defined as an elevation in $\mathrm{CK}$ to $\geq 2 \mathrm{x}$ upper limit of normal (ULN) and a rise in CK-MB or troponin to $\geq 3 \mathrm{x}$ ULN in the presence of ischaemic symptoms or ischaemic ECG changes. Target vessel revascularisation (TVR) was defined as any repeat revascularisation within the vessel of the target lesion. Target lesion revascularisation (TLR) required revascularisation of a stenosis within the stent or the 5-mm borders adjacent to the stent. Stent thrombosis (ST) was defined according to the Academic Research Consortium (ARC) definitions ${ }^{24}$. Bleeding was classified in accordance with the definition by the BARC, as well as the TIMI and the GUSTO definition ${ }^{25}$. Since the BARC definition was only recently published, we refrained from reporting BARC bleeding types 1 and 2 due to difficulties in categorising objectively such events in a retrospective fashion. BARC bleeding type $3 \mathrm{a}$ was defined as an overt bleeding event plus a drop in haemoglobin of 3 to $5 \mathrm{~g} / \mathrm{dl}$ or any transfusion in the setting of overt bleeding; type $3 \mathrm{~b}$ was defined as overt bleeding plus haemoglobin drop $\geq 5 \mathrm{~g} / \mathrm{dl}$, cardiac tamponade, bleeding requiring surgical intervention for control, and bleeding requiring intravenous vasoactive agents; type $3 \mathrm{c}$ was documented in the presence of intracranial haemorrhage or intraocular bleeding. BARC bleeding type 4 compromised perioperative intracranial bleeding, reoperation after closure of sternotomy for the purpose of controlling bleeding, and transfusion of $\geq 5$ units packed red blood cells within 48 hours, and was adjudicated by a cardiovascular surgeon (TC). Type $5 \mathrm{a}$ and type $5 \mathrm{~b}$ were determined as probable and definite fatal bleeding, respectively. All cerebrovascular events were reviewed and adjudicated by two board certified neurologists (SJ, HM) and classified as ischaemic stroke, intracranial haemorrhage, transient ischaemic attack and unclear cerebrovascular events. Ischaemic stroke was diagnosed in case of a focal neurological deficit (motor or sensory deficit, dysarthria, aphasia, visual loss) with duration of $\geq 24$ hours and/or imaging documentation of ischaemia and exclusion of intracranial bleeding. Transient ischaemic attack was defined as a neurological deficit with resolution of symptoms within 24 hours and without evidence of ischaemic brain injury from neuroimaging. An unclear neurologic event comprised all events reported by the patients without appropriate documentation to allow further classification into ischaemic stroke or transient ischaemic attack. In case of multiple events in one patient, only the first event in each event category was used for the purpose of this analysis.

\section{STATISTICAL ANALYSIS}

The baseline clinical and procedural characteristics and the medications at discharge were presented as counts and percentages $(\%)$ for categorical variables and as mean and standard deviation (SD) for continuous variables. Differences between the two groups ( $\mathrm{AF}$ and absence of AF) were performed using chi-square test for categorical variables and Student's t-test for continuous variables. Incidence rates (IR) per 100 patient years (PY) were reported rather than crude event rates to account for potential differences in follow-up time. We performed Cox proportional hazard models, with initial adjustment for type of stent and full adjustment in a multivariable analysis for age, gender, hypertension, hyperlipidaemia, diabetes, smoking, renal impairment, LVEF and ACS to compare the clinical outcomes between patients with and without AF at baseline. Hazard ratios and Kaplan-Meier curves with $95 \%$ confidence intervals were constructed for the time from index PCI until the end of four years. We further categorised the AF group according to onset (preexisting AF vs. new onset periprocedurally), baseline risk according to $\mathrm{CHA}_{2} \mathrm{DS}_{2}$-VASc score, type of AF (permanent, persistent or paroxysmal), and compared the clinical outcomes of these groups, separately, to those presenting with no AF at baseline. Then, we performed landmark analyses according to a prespecified landmark point at one year (360 days) or six months (180 days) and estimated hazard ratios and cumulative IRs separately for events up to one year/six months, and from after one year/six months until the end of follow-up at four years. Stratified analyses were performed by prespecified baseline characteristics and $\chi 2$ test was used to assess the interaction between presence or absence of AF and these characteristics. Statistical analyses were performed using STATA release 11.2 (Stata Corp., College Station, TX, USA). All p-values are two-sided. 


\section{Results}

Among 6,308 patients undergoing PCI with at least one DES between April 2002 and March 2009, 87 patients were excluded since they were not followed up after index PCI, and 180 patients were excluded due to indications for oral anticoagulation other than AF. Therefore, 6,041 patients were included in the analysis.

AF was documented in 323 patients (5.3\%). Two patients had undergone radiofrequency ablation prior to inclusion into the registry and one patient had undergone left atrial appendage occlusion prior to inclusion. Among patients with AF, 26 patients $(8.0 \%)$ had an INR $>2$ at the time of PCI, and a radial access was chosen in a single patient only, due to chronic occlusion of the iliac arteries bilaterally. Baseline characteristics of all patients undergoing PCI with or without AF are summarised in Table 1. Patients with AF were older ( $72 \pm 9$ years vs. $63 \pm 12$ years, $\mathrm{p}<0.001)$, had a higher prevalence of hypertension ( $66 \%$ vs. $57 \%, \mathrm{p}=0.002)$, renal failure ( $5 \%$ vs. $3 \%, \mathrm{p}=0.03)$, and reduced left ventricular ejection fraction $(50 \pm 13 \%$ vs. $54 \pm 12 \%, \mathrm{p}<0.001)$. Conversely, the prevalence of dyslipidaemia ( $48 \%$ vs. $53 \%$, p=0.03), smoking ( $43 \%$ versus $52 \%$, $\mathrm{p}=0.001)$ and a family history of CAD (22\% vs. $28 \%, \mathrm{p}=0.01)$ was lower in patients with AF. Procedural characteristics and medications at the time of discharge are shown in Table 2 and Table 3. Periprocedural administration of glycoprotein IIb/IIIa inhibitors was less frequent among patients with $\mathrm{AF}$ as compared to those without $(17 \%$ vs. $23 \%, \mathrm{p}=0.02)$. A CHADS $_{2}$ score $\geq 2$ was recorded among 203 AF patients (62\%). 315 patients (98\%) were discharged on aspirin and 321 patients (99\%) on clopidogrel, and 62 patients (19.2\%) were discharged on oral anticoagulation; in addition, 69 patients $(21 \%)$ were recommended to reinstall VKA within three months after the procedure. Amiodarone and digoxin were prescribed to $56(17.3 \%)$ and $22(5.6 \%)$ patients with AF, respectively. At the end of follow-up, $40.5 \%$ and $3.8 \%$ of the patients with and without AF were on oral anticoagulation $(\mathrm{p}<0.001)$, respectively. Adherence to aspirin amounted to $90.7 \%$ among patients with AF, and to $67.4 \%$ among patients without $\mathrm{AF} p<0.0001$ ); no difference with regard to clopidogrel intake was observed at the end of followup $(22.4 \%$ without $\mathrm{AF}$ vs. $20.5 \%$ with $\mathrm{AF}, \mathrm{p}=0.50)$.

\section{CLINICAL OUTCOME}

Among patients with AF, 19 patients underwent radiofrequency ablation and two patients underwent percutaneous left atrial appendage occlusion during the study period. Patients with AF had a higher risk of the primary composite endpoint after initial (HR 2.08, 95\% CI 1.66-2.61, p<0.0001) and full adjustment (HR $1.59,95 \%$ CI 1.26-2.00, $\mathrm{p}<0.0001)$ throughout four years of follow-up with a similar hazard during the first (HR 1.67, 95\% CI $1.20-2.32, \mathrm{p}=0.003$ ) and subsequent years (HR 1.68, 95\% CI 1.19-2.37, $\mathrm{p}=0.003$ ) (Table 4, Figure 1). Patients with new-onset $\mathrm{AF}$ were observed to have a higher risk of adverse outcome as compared to patients without AF (HR 2.04, 95\% CI 1.38-3.00,

Table 1. Baseline characteristics.

\begin{tabular}{|c|c|c|c|c|}
\hline & Overall & $\begin{array}{c}\text { Absence of atrial } \\
\text { fibrillation }\end{array}$ & Atrial fibrillation & $p$ \\
\hline Total (n) & 6,041 & 5,718 & 323 & - \\
\hline Age yr (SD) & $63.9(11.7)$ & $63.4(11.6)$ & 71.9 (8.9) & $<0.001$ \\
\hline Sex, male, n (\%) & $4,555(75.4)$ & $4,318(75.5)$ & $237(73.4)$ & 0.39 \\
\hline BMI mean $\mathrm{kg} / \mathrm{m}^{2}(\mathrm{SD})$ & $27.3(4.3)$ & $27.3(4.3)$ & $27.3(4.7)$ & 0.90 \\
\hline \multicolumn{5}{|l|}{ Cardiovascular risk factors } \\
\hline Hypertension, n (\%) & $3,477(57.6)$ & $3,264(57.1)$ & $213(65.9)$ & 0.002 \\
\hline Dyslipidaemia, n (\%) & $3,229(53.5)$ & $3,075(53.8)$ & $154(47.7)$ & 0.033 \\
\hline Diabetes mellitus, n (\%) & $1,069(17.7)$ & $1,000(17.5)$ & $69(21.4)$ & 0.08 \\
\hline Smoking at baseline, $\mathrm{n}(\%)$ & $3,105(51.4)$ & 2,967 (51.9) & $138(42.7)$ & 0.001 \\
\hline Anaemia at baseline, n (\%) & $1,278(21.2)$ & $83(25.7)$ & $1,195(20.9)$ & 0.040 \\
\hline Family history of CAD, $\mathrm{n}(\%)$ & $1,694(28)$ & $1,623(28.4)$ & $71(22)$ & 0.013 \\
\hline \multicolumn{5}{|l|}{ Clinical features } \\
\hline Renal failure (creatinine $\geq 200 \mu \mathrm{mol} / \mathrm{l}$ ), $\mathrm{n}(\%)$ & $166(2.7)$ & $151(2.6)$ & $15(4.6)$ & 0.032 \\
\hline Congestive heart failure & - & - & $137(42.4)$ & - \\
\hline Prior stroke or TIA & - & - & $35(10.8)$ & - \\
\hline LV ejection fraction mean (SD) & $54.1(11.9)$ & $54.3(11.8)$ & $50.3(12.9)$ & $<0.001$ \\
\hline LV ejection fraction $<50 \%, \mathrm{n}(\%)$ & $127(2.1)$ & $116(2)$ & $11(3.4)$ & 0.09 \\
\hline Acute coronary syndrome, n (\%) & $3,294(54.5)$ & $3,138(54.9)$ & $156(48.3)$ & 0.021 \\
\hline UA/Non-ST-elevation MI & $1,726(52.4)$ & $1,643(52.4)$ & $83(53.2)$ & 0.84 \\
\hline ST-elevation MI & $1,566(47.6)$ & $1,493(47.6)$ & $73(46.8)$ & - \\
\hline
\end{tabular}



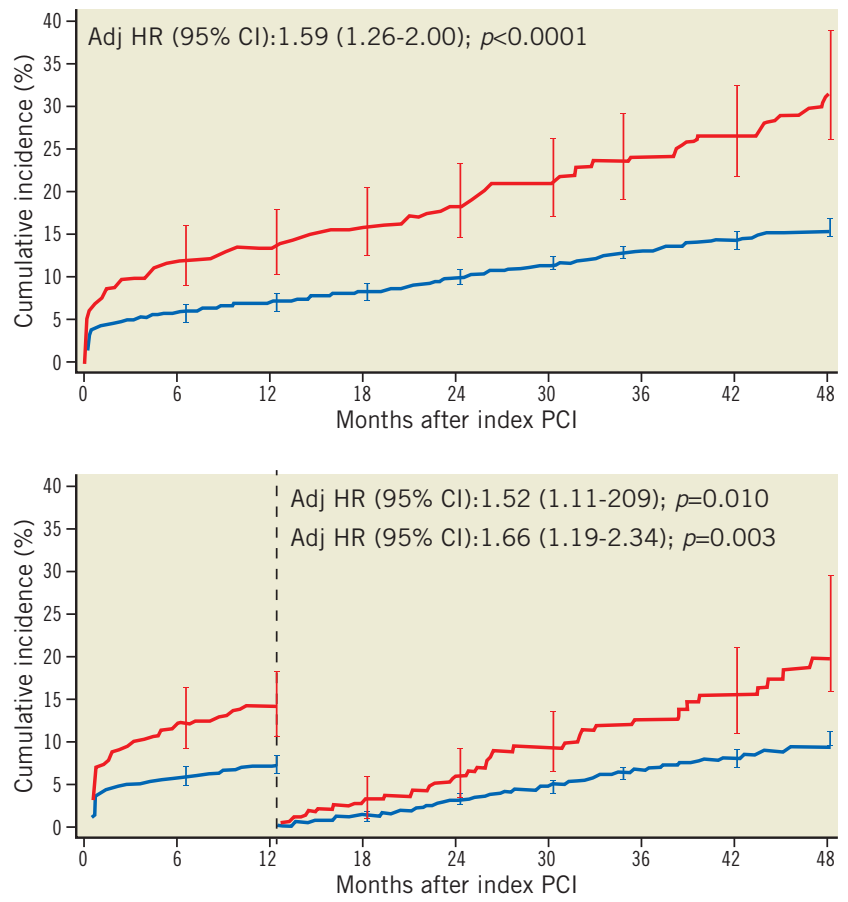

Number at risk

$\begin{array}{llllllllll}\text { AF } & 323 & 285 & 279 & 265 & 229 & 191 & 143 & 98 & 72\end{array}$

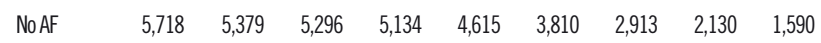

Figure 1. Primary composite outcome of all-cause mortality, myocardial infarction, stroke, and BARC bleeding type $3 b, 3 c, 5 a$, and $5 \mathrm{~b}$ through 4 years of follow-up and landmark analysis with the landmark set at 1 year. The red line indicates patients with and the blue line patients without atrial fibrillation at baseline.

$\mathrm{p}<0.0001$ ), and a strong trend towards adverse outcome was noted among patients with pre-existing AF (HR 1.43, 95\% CI 0.99-2.08, $\mathrm{p}=0.06$ ) (Figure 2).

Patients with AF had a higher risk of all-cause death after initial (HR 2.43, 95\% CI 1.85-3.19, p<0.001), and full adjustment (HR $1.67,95 \%$ CI 1.27-2.20, $\mathrm{p}<0.003$ ) (Table 4, Figure 3) up to four years. In a landmark analysis with cut-off set at one year, the risk of all-cause mortality increased steadily during the first (HR 1.51, 95\% CI 1.01-2.27, $\mathrm{p}=0.047$ ) and subsequent years (HR 1.85, 95\% CI 1.27-2.69, $\mathrm{p}=0.001)$. AF was associated with an increased risk of ischaemic stroke (HR 3.08, 95\% CI 1.45-6.56, $\mathrm{p}=0.003$ ) and intracranial bleeding (HR 4.28, 95\% CI 1.36-13.48, $\mathrm{p}=0.013$ ) after initial and full adjustment (Table 4). There was no difference between patients with and without AF in terms of ARC-defined ST (Table 5).

A graduated increase in the incidence rate (IR) of the primary endpoint was observed with increasing $\mathrm{CHA}_{2} \mathrm{DS}_{2}$-VASc scores (adjusted $\mathrm{p}$ for trend $<0.0001$ ) (Figure 4). At the same time, the risk of adverse clinical outcome tended to increase with increasing mOBRI score (Table 6).

A stratified analysis of the primary composite endpoint across major subgroups showed a fourfold increased risk among patients

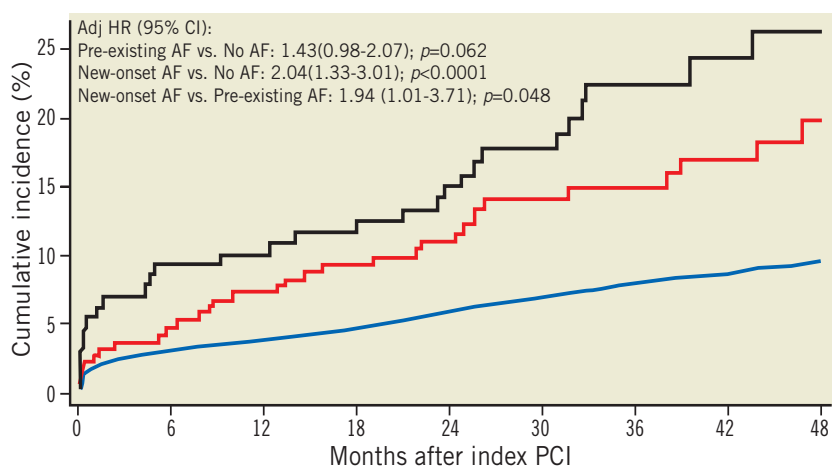

$\begin{array}{lccccccccc}\text { Number at risk } & & & & & & & & & \\ \text { New-onset AF } & 129 & 117 & 116 & 110 & 98 & 78 & 52 & 39 & 25 \\ \text { Pre-existing AFF } & 194 & 185 & 180 & 173 & 147 & 124 & 98 & 66 & 53 \\ \text { No AF } & 5,718 & 5,532 & 5,469 & 5,324 & 4,817 & 4,000 & 3,082 & 2,261 & 1,694\end{array}$

Figure 2. Primary composite outcome of all-cause mortality, myocardial infarction, stroke, and BARC bleeding type $3 b, 3 c, 5 a$, and $5 b$ through four years of follow-up according to pre-existing atrial fibrillation or new onset of atrial fibrillation. The black line represents patients with new-onset atrial fibrillation during the course of the index hospitalisation. The red line represents patients with pre-existing atrial fibrillation prior to hospital admission. The blue line indicates patients without atrial fibrillation.
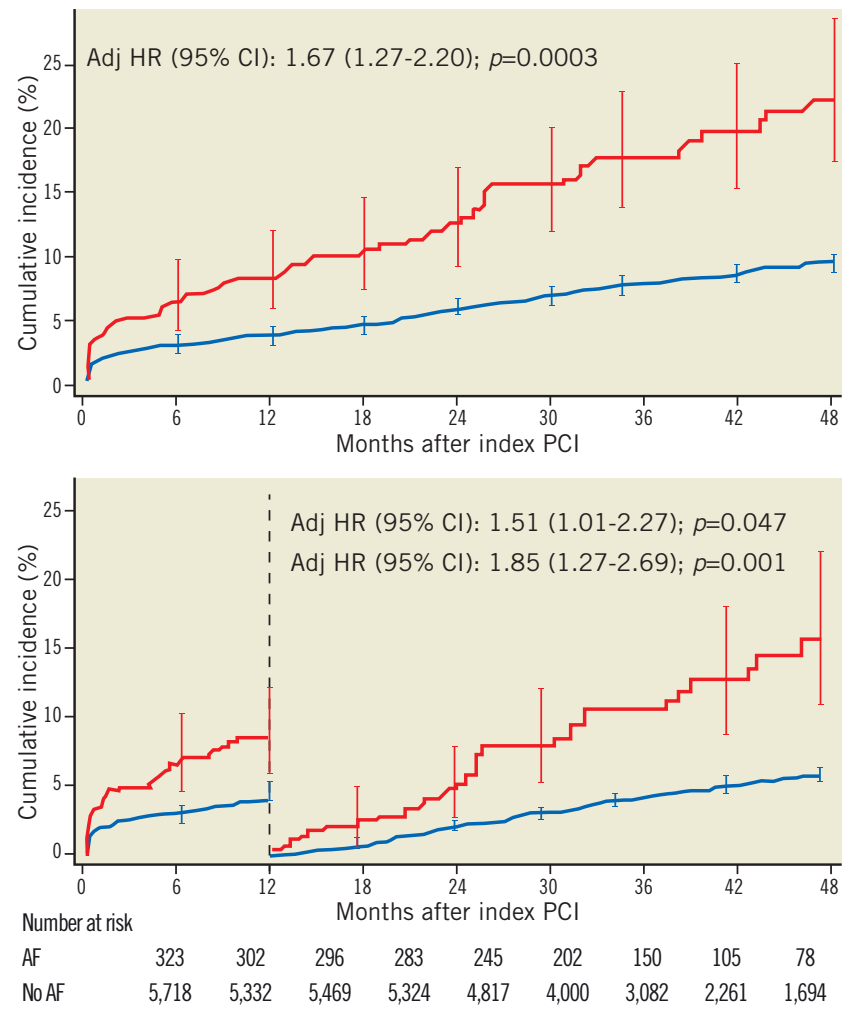

Figure 3. All-cause mortality up to four years of follow-up and landmark analysis at one year. The red line indicates patients with and the blue line patients without atrial fibrillation at baseline. 
Table 2. Procedural characteristics.

\begin{tabular}{|c|c|c|c|c|}
\hline & Overall & $\begin{array}{c}\text { Absence of atrial } \\
\text { fibrillation }\end{array}$ & Atrial fibrillation & $p$ \\
\hline Total (n) & 6,041 & 5,718 & 323 & \\
\hline Type of stent & & & & 0.84 \\
\hline Early-generation DES* & $3,941(65.2)$ & $3,732(65.3)$ & 209 (64.7) & \\
\hline Newer-generation DES $\pi$ & $2,100(34.8)$ & $1,986(34.7)$ & $114(35.3)$ & \\
\hline Multivessel treatment, n (\%) & $1,161(19.3)$ & $1,104(19.3)$ & $57(17.7)$ & 0.47 \\
\hline No of vessels treated per patient, n (SD) & $1.2(0.4)$ & $1.2(0.4)$ & $1.2(0.4)$ & 0.71 \\
\hline No of lesions treated per patient, n (SD) & $1.6(0.8)$ & $1.6(0.8)$ & $1.6(0.8)$ & 0.82 \\
\hline \multicolumn{5}{|l|}{ Target vessel } \\
\hline Number of stents implanted, $n$ (SD) & $1.8(1)$ & $1.8(1)$ & $1.8(1)$ & 0.92 \\
\hline Average stent diameter, mm (SD) & $2.9(0.5)$ & $2.9(0.5)$ & $2.8(0.4)$ & 0.016 \\
\hline Total stent length, mm (SD) & $30.3(18.5)$ & $30.2(18.4)$ & $31.3(19.8)$ & 0.28 \\
\hline Left main, n (\%) & $168(2.8)$ & $158(2.8)$ & $10(3.1)$ & 0.72 \\
\hline Left anterior descending, n (\%) & 2,973 (49.3) & $2,816(49.4)$ & $157(48.8)$ & 0.83 \\
\hline Left circumflex, n (\%) & $1,573(26.1)$ & $1,504(26.4)$ & $69(21.4)$ & 0.05 \\
\hline Right coronary artery, n (\%) & $2,148(35.6)$ & 2,025 (35.5) & $123(38.2)$ & 0.32 \\
\hline Arterial bypass graft, n (\%) & $14(0.2)$ & $14(0.2)$ & $0(0)$ & 0.37 \\
\hline Saphenous vein graft, n (\%) & $161(2.7)$ & $147(2.6)$ & $14(4.3)$ & 0.055 \\
\hline $\begin{array}{l}\text { Length of hospital stay after PCI }{ }^{\text {tr }} \\
\text { (median, } 25^{\text {th }} \text { to } 75^{\text {th }} \text { percentile) }\end{array}$ & 1 (1 to 2 ) & 1 (1 to 2 ) & 1 (1 to 4$)$ & $<0.001$ \\
\hline
\end{tabular}

with $\mathrm{AF}$ and renal failure (HR 3.80, 95\% CI 1.84-7.85), while patients with AF but without renal failure showed only a $47 \%$ increase in relative risk (HR 1.47, 95\% CI 1.14-1.88). The difference was marginally significant $\left(\mathrm{p}_{\text {interaction }}=0.05\right)$ (Figure 5). Outcome among patients with AF treated with or without oral anticoagulation in addition to dual antiplatelet therapy is summarised in Figure 6.

Table 3. Discharge medications.

\begin{tabular}{|c|c|c|c|c|}
\hline & Overall & $\begin{array}{l}\text { Absence of atrial } \\
\text { fibrillation }\end{array}$ & Atrial fibrillation & $p$ \\
\hline Total (n) & 6,041 & 5,718 & 323 & \\
\hline Aspirin, n (\%) & $5,916(97.9)$ & $5,601(97.9)$ & 315 (97.5) & 0.55 \\
\hline Clopidogrel, n (\%) & $5,961(98.7)$ & $5,640(98.6)$ & $321(99.4)$ & 0.45 \\
\hline Oral anticoagulation, n (\%) & $62(1.0)$ & 0 & $62(19.2)$ & $<0.001$ \\
\hline Beta-blocker, n (\%) & $3,724(61.9)$ & $3,524(61.8)$ & $200(62.3)$ & 0.87 \\
\hline ACE inhibitor, n (\%) & $3,150(52.3)$ & $2,964(52)$ & $186(57.9)$ & 0.038 \\
\hline AT II inhibitor, n (\%) & $878(14.6)$ & $829(14.5)$ & $49(15.3)$ & 0.72 \\
\hline Calcium antagonist, n (\%) & $616(10.2)$ & $573(10.1)$ & $43(13.4)$ & 0.055 \\
\hline Statin, n (\%) & $5,075(84.3)$ & $4,833(84.8)$ & $242(75.4)$ & $<0.001$ \\
\hline Oral antidiabetic, n (\%) & $650(10.8)$ & $608(10.7)$ & $42(13.1)$ & 0.18 \\
\hline Insulin, n (\%) & $319(5.3)$ & $295(5.2)$ & $24(7.5)$ & 0.07 \\
\hline Diuretics, n (\%) & $1,023(17)$ & $885(15.5)$ & $138(43)$ & $<0.001$ \\
\hline Proton pump inhibitor, n (\%) & $1,155(19.2)$ & $1,074(18.8)$ & $81(25.2)$ & 0.005 \\
\hline GP $\|\mathrm{a} / \mathrm{I}\| \mathrm{b}$ & $1,362(22.5)$ & $1,306(22.8)$ & $56(17.3)$ & 0.021 \\
\hline
\end{tabular}


Table 4. Clinical outcome.

\begin{tabular}{|c|c|c|c|c|c|c|}
\hline & $\begin{array}{c}\text { Atrial } \\
\text { fibrillation }\end{array}$ & $\begin{array}{c}\text { Absence of } \\
\text { atrial fibrillation }\end{array}$ & $\begin{array}{l}\text { Initial adj HR } \\
(95 \% \mathrm{CI})\end{array}$ & crude- $p$ & $\begin{array}{c}\text { Full adj HR } \\
(95 \% \mathrm{Cl})\end{array}$ & Adj-p \\
\hline & 323 & 5,718 & & & & \\
\hline Death $\mathrm{n}(\%)$ & $59(22.5)$ & $458(9.6)$ & $2.43(1.85-3.19)$ & $<0.0001$ & $1.67(1.27-2.20)$ & 0.0003 \\
\hline \multicolumn{7}{|l|}{ Cardiac events } \\
\hline Cardiac death, $\mathrm{n}(\%)$ & $31(11.8)$ & $233(4.7)$ & $2.47(1.70-3.60)$ & $<0.0001$ & $1.84(1.26-2.71)$ & 0.002 \\
\hline Myocardial infarction (MI), n (\%) & $16(6.5)$ & $223(4.8)$ & $1.36(0.82-2.25)$ & 0.24 & $1.37(0.81-2.30)$ & 0.24 \\
\hline Q-wave $\mathrm{MI}, \mathrm{n}(\%)$ & $7(2.7)$ & $91(2.0)$ & $1.45(0.67-3.13)$ & 0.34 & $1.66(0.75-3.66)$ & 0.21 \\
\hline Non-Q-wave MI, n (\%) & $9(3.7)$ & $122(2.7)$ & $1.39(0.71-2.73)$ & 0.34 & $1.30(0.65-2.59)$ & 0.46 \\
\hline Target lesion revascularisation & $25(10.3)$ & $473(9.4)$ & $0.99(0.66-1.48)$ & 0.97 & $1.07(0.71-1.60)$ & 0.76 \\
\hline Target vessel revascularisation & 39 (16.3) & $740(14.8)$ & $0.99(0.72-1.36)$ & 0.94 & $1.07(0.77-1.48)$ & 0.69 \\
\hline Death/MI & $73(27.6)$ & $649(13.6)$ & $2.15(1.69-2.73)$ & $<0.0001$ & $1.62(1.27-2.08)$ & 0.0001 \\
\hline Cardiac death/MI & $46(17.7)$ & 431 (8.9) & $2.02(1.49-2.73)$ & $<0.0001$ & $1.69(1.24-2.31)$ & 0.001 \\
\hline \multicolumn{7}{|l|}{ Neurologic events } \\
\hline Ischaemic stroke & $9(3.4)$ & $38(0.8)$ & $4.47(2.16-9.24)$ & $<0.0001$ & $3.08(1.45-6.56)$ & 0.003 \\
\hline TIA & $2(0.6)$ & $21(0.4)$ & $1.79(0.42-7.63)$ & 0.43 & $1.16(0.27-5.08)$ & 0.84 \\
\hline Unclear neurologic event & $2(0.9)$ & $7(0.2)$ & $5.47(1.14-26.36)$ & 0.034 & $3.04(0.58-15.95)$ & 0.19 \\
\hline \multicolumn{7}{|l|}{ Bleeding events } \\
\hline BARC bleeding-3a & $10(3.3)$ & $81(1.5)$ & $2.22(1.15-4.28)$ & 0.017 & $1.79(0.91-3.51)$ & 0.09 \\
\hline BARC bleeding-3b & $5(1.6)$ & $83(1.5)$ & $1.08(0.44-2.67)$ & 0.86 & $0.85(0.34-2.11)$ & 0.72 \\
\hline BARC bleeding-3c & $4(1.9)$ & $17(0.4)$ & $4.50(1.51-13.38)$ & 0.007 & $4.28(1.36-13.48)$ & 0.013 \\
\hline BARC bleeding-4 & $1(0.3)$ & $8(0.2)$ & $2.41(0.30-19.24)$ & 0.41 & $2.98(0.34-26.08)$ & 0.32 \\
\hline BARC bleeding-5a & $0(0)$ & $1(0.02)$ & $5.89(0.24-144.3)$ & 1.00 & & \\
\hline BARC bleeding- $5 b$ & $1(0.3)$ & $4(0.1)$ & $4.37(0.49-39.2)$ & 0.19 & & \\
\hline TIMI major bleeding & $10(3.7)$ & $92(1.7)$ & $1.98(1.03-3.81)$ & 0.040 & 1.59 (0.81-3.09) & 0.18 \\
\hline TIMI minor bleeding & $10(3.3)$ & $89(1.6)$ & $2.03(1.05-3.90)$ & 0.034 & $1.68(0.86-3.29)$ & 0.13 \\
\hline GUSTO severe bleeding & $9(3.4)$ & $69(1.4)$ & $2.40(1.20-4.80)$ & 0.014 & $1.87(0.92-3.81)$ & 0.086 \\
\hline GUSTO moderate bleeding & $6(2.0)$ & $58(1.0)$ & $1.85(0.80-4.29)$ & 0.15 & $1.25(0.53-2.92)$ & 0.61 \\
\hline \multicolumn{7}{|l|}{ Composite outcomes } \\
\hline Death/MI/ischaemic stroke & 79 (31.0) & $685(14.7)$ & $2.21(1.75-2.80)$ & $<0.0001$ & $1.67(1.32-2.12)$ & $<0.0001$ \\
\hline Cardiac death/MI/ischaemic stroke & $54(22.0)$ & $471(10.1)$ & $2.18(1.65-2.89)$ & $<0.0001$ & $1.79(1.32-2.12)$ & $<0.0001$ \\
\hline $\begin{array}{l}\text { Death/Ml/ischaemic stroke/BARC } \\
\text { bleeding } 3 \mathrm{~b} / 3 \mathrm{c} / 5 \mathrm{a} / 5 \mathrm{~b}\end{array}$ & $83(34.0)$ & $762(16.4)$ & $2.08(1.66-2.61)$ & $<0.0001$ & $1.59(1.26-2.00)$ & $<0.0001$ \\
\hline
\end{tabular}

Table 5. Stent thrombosis.

\begin{tabular}{|c|c|c|c|c|c|c|}
\hline & $\begin{array}{c}\text { Atrial } \\
\text { fibrillation }\end{array}$ & $\begin{array}{l}\text { Absence of } \\
\text { atrial fibrillation }\end{array}$ & $\begin{array}{l}\text { Initial adj HR } \\
(95 \% \mathrm{CI})\end{array}$ & crude- $p$ & $\begin{array}{c}\text { Full adj HR } \\
(95 \% \mathrm{Cl})\end{array}$ & Adj-p \\
\hline & 323 & 5,718 & & & & \\
\hline \multicolumn{7}{|l|}{ Definite ST } \\
\hline Early (0 to 30 days) & $2(0.6)$ & $54(1.0)$ & $0.66(0.16-2.71)$ & 0.57 & $0.68(0.16-2.86)$ & 0.60 \\
\hline Late (31 to 360 days) & $1(0.3)$ & $14(0.3)$ & $1.30(0.17-9.92)$ & 0.80 & $1.14(0.14-8.99)$ & 0.90 \\
\hline Very late (361 to 1,440 days) & $1(0.5)$ & $61(1.5)$ & $0.32(0.04-2.29)$ & 0.26 & $0.40(0.05-2.94)$ & 0.37 \\
\hline Overall ( 0 to 1,440 days) & $4(1.5)$ & $129(2.7)$ & $0.58(0.21-1.56)$ & 0.28 & $0.64(0.24-1.76)$ & 0.39 \\
\hline \multicolumn{7}{|l|}{ Definite or probable ST } \\
\hline Early (0 to 30 days) & $17(5.3)$ & $177(3.1)$ & $1.73(1.05-2.84)$ & 0.031 & $1.62(0.97-2.70)$ & 0.064 \\
\hline Late (31 to 360 days) & $2(0.7)$ & $30(0.5)$ & $1.22(0.29-5.10)$ & 0.79 & $1.08(0.25-4.61)$ & 0.92 \\
\hline Very late (361 to 1,440 days) & $2(0.9)$ & $115(2.9)$ & $0.34(0.08-1.37)$ & 0.13 & $0.37(0.09-1.50)$ & 0.16 \\
\hline Overall ( 0 to 1,440 days) & $21(6.8)$ & $322(6.5)$ & $1.21(0.78-1.88)$ & 0.39 & $1.17(0.75-1.84)$ & 0.49 \\
\hline
\end{tabular}


Table 6. Primary outcome.

\begin{tabular}{|c|c|c|c|c|c|}
\hline & n (CIR) & $\begin{array}{c}\text { Crude HR }(95 \% \\
\text { CI) }\end{array}$ & crude- $p$ & $\begin{array}{c}\text { Adj HR }(95 \% \\
\text { CI) }\end{array}$ & Adj-p \\
\hline Absence of atrial fibrillation & $762(16.4)$ & Reference & & Reference & \\
\hline \multicolumn{6}{|l|}{ Atrial fibrillation } \\
\hline Low risk $(\mathrm{mOBRI}=0)$ & $2(6.9)$ & $0.77(0.19-3.09)$ & 0.72 & $1.34(0.33-5.43)$ & 0.68 \\
\hline Intermediate risk (mOBRI $=1-2)$ & $74(3.4)$ & $2.04(1.59-2.62)$ & $<0.001$ & $1.53(1.18-1.97)$ & 0.001 \\
\hline High risk (mOBRI >2) & $7(18.4)$ & $3.36(1.51-7.51)$ & 0.003 & $1.83(0.81-4.13)$ & 0.14 \\
\hline
\end{tabular}

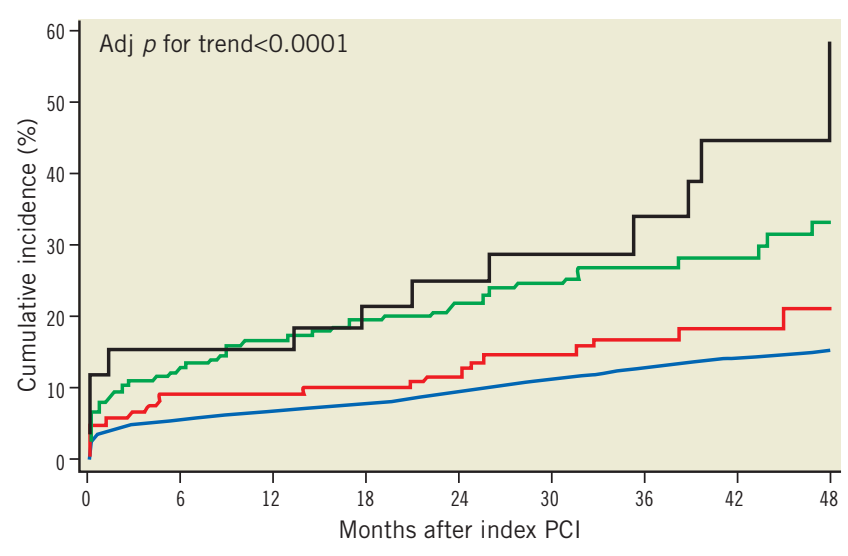

Figure 4. Primary outcome up to four years of follow-up according to severity of atrial fibrillation based on $C H A_{2} D S_{2}-V A S c$ score at baseline. The black line shows the Kaplan-Meier curve for patients with a $\mathrm{CHA}_{2} D \mathrm{~S}_{2}$-VASc score $>5$. The green line represents patients with a $C H A_{2} D S_{2}-V A S c$ score of $4-5$. The red line represents patients with a $\mathrm{CHA}_{2} D \mathrm{~S}_{2}$-VASc score of 1-3. The blue line indicates patients without atrial fibrillation.

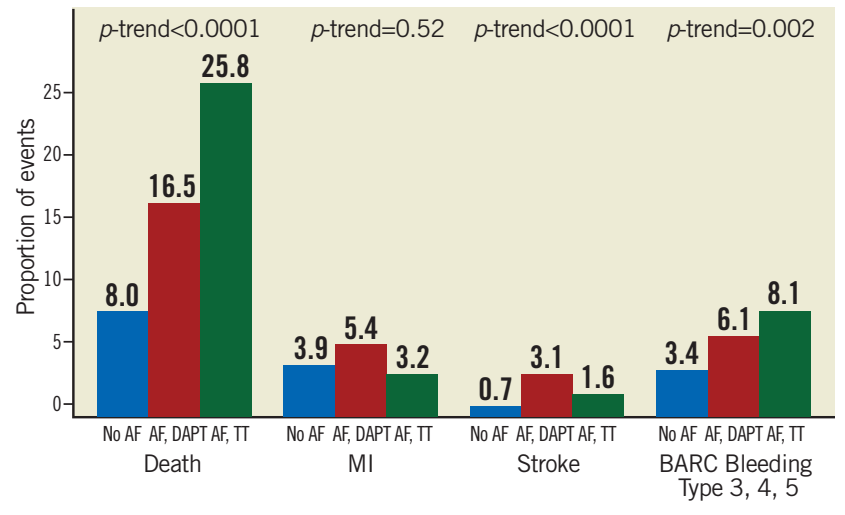

Figure 6. Stratified analysis according to atrial fibrillation treated with or without oral anticoagulation at discharge: single components of the primary outcome in patients with no atrial fibrillation (blue bars), patients with atrial fibrillation on dual antiplatelet therapy without oral anticoagulation (red bars), and patients with atrial fibrillation on triple antithrombotic therapy (green bars).

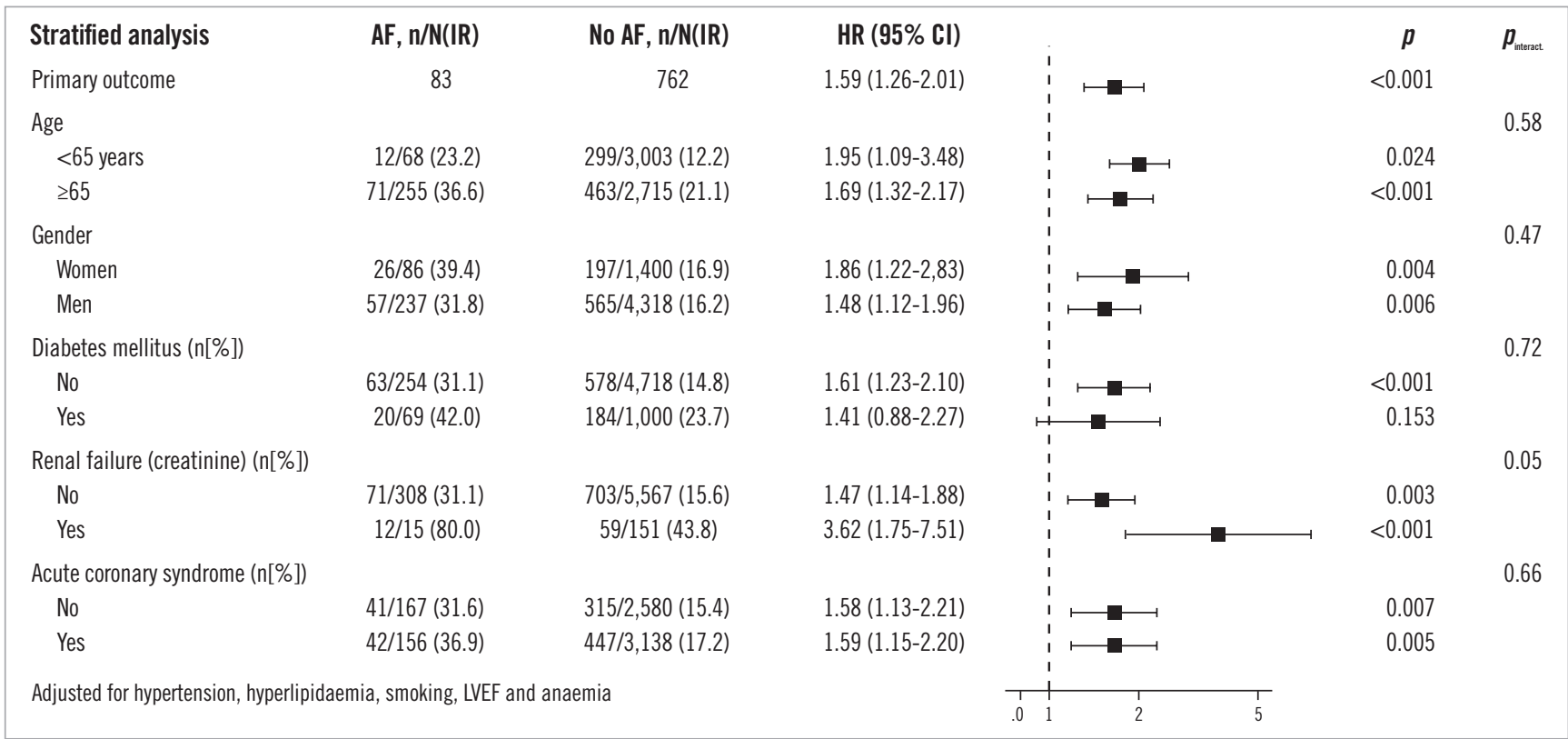

Figure 5. Stratified analysis of the primary composite outcome across major subgroups. 


\section{Discussion}

The principal findings of the present analysis can be summarised as follows: 1) a diagnosis of AF was documented in 5.3\% of unselected patients undergoing PCI; 2) AF was associated with an increased risk of the primary composite endpoint of all-cause mortality, non-fatal MI, ischaemic stroke, and types 3b, 3c, 5a, 5b BARC bleeding through four years; 3) AF was also associated with an increased risk of the individual endpoints of all-cause mortality, ischaemic stroke, and intracranial bleeding; 4) the increased risk was directly related to increasing $\mathrm{CHA}_{2} \mathrm{DS}_{2}$-VASc scores; 5) AF in combination with renal failure portended a particularly poor long-term outcome.

The prevalence of $\mathrm{AF}$ in this unselected patient population undergoing PCI with the unrestricted use of DES amounted to $5.3 \%$, which is consistent with previous reports of patients with stable $\mathrm{CAD}$ and acute $\mathrm{MI}^{2-7}$. In line with established risk factors for $\mathrm{AF}^{8,9}$, patients with AF were older and had a higher prevalence of hypertension and compromised left ventricular ejection fraction. Of note, only a minority of patients were treated with triple antiplatelet therapy, while most patients were discharged on DAPT.

Patients with AF had a higher risk of the primary composite outcome as well as the individual endpoints including all-cause mortality, ischaemic stroke, and intracranial bleeding compared to patients without AF, whereas there were no differences in terms of non-fatal MI, ST, or repeat revascularisation procedures. Landmark analyses for the primary composite endpoint as well as all-cause mortality demonstrated a steady risk during the entire duration of follow-up with no differences between the first year and subsequent years. The association of AF with all-cause mortality corroborated the findings of previous studies ${ }^{8-10,14}$, persisted even after full adjustment of baseline characteristics, and was not accompanied by differences in the incidence of non-fatal MI or ST, suggesting a potential relationship with the occurrence of ischaemic and haemorrhagic strokes. The $\mathrm{CHA}_{2} \mathrm{DS}_{2}-\mathrm{VASc}$ score directly correlated with the risk of the primary composite endpoint.

We observed a particularly increased risk of adverse outcome among patients with new-onset AF. This observation is in line with a community-based study, which showed an excess mortality within the first four months after newly diagnosed AF (HR 9.62, 95\% CI 8.93-10.32) as compared to beyond the first four months (HR 1.66, 95\% CI 1.591.73). Similarly, patients with acute MI complicated by AF were found to have an increased risk of all-cause mortality (HR 1.82, 95\% CI 1.39$2.39, \mathrm{p}<0.001$ ) and stroke (HR 2.29, 95\% CI 1.43-3.68, $<<0.001$ ) up to three years of follow-up in the OPTIMAAL experience ${ }^{10}$.

Patients with AF were at increased risk of both ischaemic stroke and intracranial bleeding. In addition, a trend towards a higher incidence of BARC bleeding type 3 a was observed in patients with AF. Oral anticoagulation was installed at discharge in $19 \%$ of patients - in a majority of patients in combination with DAPT - whereas a recommendation to recommence oral anticoagulation within three months of DES implantation (after discontinuation of either aspirin or clopidogrel) was made in another $22 \%$ of patients. Treatment recommendations from the ESC Working Group on Thrombosis support uninterrupted VKA treatment as an alternative to heparin bridging therapy in the periprocedural phase, endorse triple therapy post-interventionally instead of temporary replacement of VKA by dual antiplatelet drug therapy, and recommend the avoidance of DES in patients with very high bleeding risk ${ }^{14}$. A North American consensus document recommends a radial access in order to reduce periprocedural bleeding, generally prefers BMS over DES, and suggests considering proton pump inhibitors (e.g., pantoprazole) for patients with triple therapy ${ }^{15}$. Antithrombotic strategies following coronary artery stenting differ between European and North American consensus documents. In elective cases, European experts recommend triple therapy for the duration of three months for patients treated with limus analogues and six months for patients treated with paclitaxel-eluting stents, and for the duration of six months in patients undergoing PCI for acute coronary syndromes irrespective of the stent. In contrast, North American guidelines recommend triple therapy for at least six months in patients with low risk of stent thrombosis and bleeding, and for 12 months in patients with high risk of stent thrombosis and low risk of bleeding. Both consensus documents were published after recruitment of our study population and did not reflect the standard of care at our institution during the inclusion phase of our registry.

In the largest randomised trial to date comparing 573 patients undergoing PCI, patients receiving dual therapy with oral anticoagulants and clopidogrel were found to have significantly fewer TIMI bleeding events compared with patients receiving triple therapy including aspirin, whereas numbers of stent thrombosis, myocardial infarction, and stroke were comparable (Dewilde W, What is the Optimal Antiplatelet and Anticoagulant Therapy in Patients with Oral Anticoagulation and Coronary Stenting (WOEST) trial. Oral presentation, ESC, Munich 2012). Among AF patients followed in a large integrated healthcare system in Northern California, oral anticoagulation reduced the risk of ischaemic stroke and allcause mortality, while increasing the risk of intracranial haemorrhage as compared to patients without oral anticoagulation ${ }^{26}$. Patients with both a diagnosis of $\mathrm{CAD}$ requiring revascularisation by PCI as well as AF represent a high-risk population at either side of the risk scale (ischaemia and bleeding). Thus, the presence of $\mathrm{CAD}$ has been associated with a strong trend towards an increased risk of thromboembolic events ${ }^{21}$ among patients with AF. At the same time, triple antithrombotic therapy in patients undergoing PCI with AF has been associated with a higher incidence of major bleeding events compared with other regimens ${ }^{27}$. Of note, risk scores for bleeding or stroke cannot be easily generalised to patients with AF undergoing PCI with DES as they do not take into consideration the risk of stent thrombosis ${ }^{21,28}$ and the duration of antithrombotic therapy. However, we did not observe a difference in the incidence of ST between patients with and without AF in the present study. Although we can only speculate how event rates in terms of ischaemic risk reduction and bleeding risk increase would have been with a more aggressive regimen of triple antithrombotic therapy, the adverse outcome of patients with AF undergoing PCI with DES requires more research as to the optimal intensity and duration of antithrombotic therapy. 
In a stratified analysis of the primary composite outcome, we observed an excessive risk for patients with both $\mathrm{AF}$ and renal failure, corroborating the results of previous reports showing an increased risk of ischaemic stroke and all-cause mortality in such patients ${ }^{29,30}$. The increased thromboembolic risk among patients with AF and renal failure may be related to elevations in inflammatory markers and a procoagulant milieu ${ }^{31}$. Moreover, renal failure has been identified as an independent predictor of major haemorrhage in a cohort of outpatients treated with oral anticoagulants ${ }^{32}$, potentially related to platelet dysfunction in patients with renal failure ${ }^{33,34}$.

\section{Limitations}

This study has several limitations. Among patients with AF, different antithrombotic regimens were applied according to the discretion of the treating physician, not following a prospectively defined regimen; even though the recommended antithrombotic regimen at discharge and during follow-up was recorded, information in terms of the intensity of anticoagulation and compliance was not available. However, patients taking oral anticoagulation for indications other than AF were excluded from the present study cohort. The current study reports on antithrombotic strategies including the use of aspirin, clopidogrel and VKA. The impact on outcome of combinations with recently introduced antiplatelet agents such as prasugrel and ticagrelor, as well as with novel antithrombotic agents such as dabigatran, rivaroxaban, and apixaban, are not reflected by the present analysis. Bleeding data were recorded as evidenced by significant changes in haemoglobin values, adverse events leading to hospitalisation and patient self-reported episodes. Due to recollection bias, minor bleeding events may have been underreported as compared with major bleeding events. We cannot differentiate whether atrial fibrillation is a risk marker or a risk factor although we adjusted for known risk factors associated with atrial fibrillation. In order to address this issue we looked into patients with newonset atrial fibrillation and observed an increased risk, suggesting that atrial fibrillation is a risk factor for adverse outcome rather than a marker.

\section{Conclusions}

Among patients with $\mathrm{CAD}$ undergoing revascularisation with the unrestricted use of DES, AF confers an increased risk of all-cause mortality, ischaemic stroke, and intracranial bleeding. The risk increase correlates with the $\mathrm{CHA}_{2} \mathrm{DS}_{2}$-VASc score. The current study provides the basis for future research investigating optimal intensity and duration of antithrombotic treatment among patients with $\mathrm{CAD}$ and $\mathrm{AF}$.

\section{Conflict of interest statement}

The authors have no conflicts of interest to declare.

\section{References}

1. Wolf PA, Abbott RD, Kannel WB. Atrial fibrillation as an independent risk factor for stroke: the Framingham study. Stroke. 1991;22:983-8.
2. Otterstad JE, Kirwan BA, Lubsen J, De Brouwer S, Fox KA, Corell P, Poole-Wilson PA; Action Investigators. Incidence and outcome of atrial fibrillation in stable symptomatic coronary disease. Scand Cardiovasc J. 2006;40:152-9.

3. Rathore SS, Berger AK, Weinfurt KP, Schulman KA, Oetgen WJ, Gersh BJ, Solomon AJ. Acute myocardial infarction complicated by atrial fibrillation in the elderly: prevalence and outcomes. Circulation. 2000;101:969-74.

4. Wong CK, White HD, Wilcox RG, Criger DA, Califf RM, Topol EJ, Ohman EM. New atrial fibrillation after acute myocardial infarction independently predicts death: the GUSTO-III experience. Am Heart J. 2000;140:878-85.

5. Eldar M, Canetti M, Rotstein Z, Boyko V, Gottlieb S, Kaplinsky E, Behar S. Significance of paroxysmal atrial fibrillation complicating acute myocardial infarction in the thrombolytic era. SPRINT and Thrombolytic Survey Groups. Circulation. 1998; 97:965-70.

6. Crenshaw BS, Ward SR, Granger CB, Stebbins AL, Topol EJ, Califf RM. Atrial fibrillation in the setting of acute myocardial infarction: the GUSTO-I experience. Global Utilization of Streptokinase and TPA for Occluded Coronary Arteries. J Am Coll Cardiol. 1997:30;406-13.

7. Goldberg RJ, Yarzebski J, Lessard D, Wu J, Gore JM. Recent trends in the incidence rates of and death rated from atrial fibrillation complicating initial acute myocardial infarction: a communitywide perspective. Am Heart J. 2002;143:519-27.

8. Benjamin EJ, Wolf PA, D'Agostino RB, Silbershatz H, Kannel WB, Levy D. Impact of atrial fibrillation on the risk of death. Circulation. 1998;98:946-52.

9. Gersh BJ, Tsang TS, Barnes ME, Seward JB. The changing epidemiology of non-valvular atrial fibrillation: the role of novel risk factors. Eur Heart J. 2005; 7:C5-C11.

10. Lehto M, Snapinn S, Dickstein K, Swedberg K, Nieminen MS; OPTIMAAL investigators. Prognostic risk of atrial fibrillation in acute myocardial infarction complicated by left ventricular dysfunction: the OPTIMAAL experience. Eur Heart J. 2005;26: 350-6.

11. Hart RG, Pearce LA, Aguilar MI. Meta-analysis: antithrombotic therapy to prevent stroke in patients who have nonvalvular atrial fibrillation. Ann Intern Med. 2007;146:857-67.

12. Jeremias A, Kaul S, Rosengart TK, Gruberg L, Brown DL. The impact of revascularization on mortality in patients with nonacute coronary artery disease. Am J Med. 2009;122:152-61.

13. Hansen ML, Sorensen R, Clausen MT, Fog-Petersen ML, Raunsø J, Gadsbøll N, Gislason GH, Folke F, Andersen SS, Schramm TK, Abildstrøm SZ, Poulsen HE, Køber L, Torp-Pedersen C. Risk of bleeding with single, dual, or triple therapy with warfarin, aspirin, and clopidogrel in patients with atrial fibrillation. Arch Intern Med. 2010;170:1433-41.

14. Lip GY, Huber K, Andreotti F, Arnesen H, Airaksinen KJ, Cuisset T, Kirchhof P, Marín F; European Society of Cardiology Working Group on Thrombosis. Management of antithrombotic therapy in atrial fibrillation patients presenting with acute coronary 
syndrome and/or undergoing percutaneous coronary intervention/ stenting. Thromb Haemost. 2010;103:13-28.

15. Faxon DP, Eikelboom JW, Berger PB, Holmes DR, Bhatt DL, Moliterno DJ, Becker RC, Angiolillo DJ. Consensus document: antithrombotic therapy in patients with atrial fibrillation undergoing coronary stenting. A North-American perspective. Thromb Haemost. 2011;106:572-84.

16. Huber K, Airaksinen KJ, Cuisset T, Marín F, Rubboli A, Lip GY. Antithrombotic therapy in patients with atrial fibrillation undergoing coronary stenting: similarities and dissimilarities between North America and Europe. Thromb Haemost. 2011;106:569-71.

17. Stettler C, Wandel S, Allemann S, Stettler C, Wandel S, Allemann S, Kastrati A, Morice MC, Schömig A, Pfisterer ME, Stone GW, Leon MB, de Lezo JS, Goy JJ, Park SJ, Sabaté M, Suttorp MJ, Kelbaek H, Spaulding C, Menichelli M, Vermeersch P, Dirksen MT, Cervinka P, Petronio AS, Nordmann AJ, Diem P, Meier B, Zwahlen M, Reichenbach S, Trelle S, Windecker S, Jüni P. Outcomes associated with drug-eluting and bare-metal stents: a collaborative network meta-analysis. Lancet. 2007;370:937-48.

18. Pisters R, Lane DA, Nieuwlaat R, de Vos CB, Crijns HJ, Lip GY. A novel user-friendly score (HAS-BLED) to assess 1-year risk of major bleeding in patients with atrial fibrillation: The Euro Heart survey. Chest. 2010;138:1093-100.

19. Räber L, Jüni P,Nüesch E, Kalesan B, Wenaweser P,Moschovitis A, Khattab AA, Bahlo M, Togni M, Cook S, Vogel R, Seiler C, Meier B, Windecker S. Long-term comparison of everolimus-eluting and sirolimus-eluting stents for coronary revacularization. $J \mathrm{Am}$ Coll Cardiol. 2011;57:2143-51.

20. Gage BF, Waterman AD, Shannon W, Boechler M, Rich WM, Radford MJ. Validation of clinical classification schemes for predicting stroke: results from the National Registry of Atrial Fibrillation. JAMA. 2001;285:2864-70.

21. Lip GY, Nieuwlaat R, Pisters R, Lane DA, Crijns HJ. Refining clinical risk stratification for predicting stroke and thromboembolism in atrial fibrillation using a novel risk factor-basedapproach: the Euro Heart survey on atrial fibrillation. Chest. 2010;137:263-72.

22. Beyth RJ, Quinn LM, Landefeld CS. Prospective evaluation of an index for predicting the risk of major bleeding in outpatients treated with warfarin. Am J Med. 1998;105:91-9.

23. Aspinall SL, DeSanzo BE, Trilli LE, Good SB. Bleeding Risk Index in an anticoagulation clinic. Assessment by indication and implications for care. J Gen Intern Med. 2005;20:1008-13.

24. Cutlip DE, Windecker S, Mehran R, Boam A, Cohen DJ, van Es GA, Steg PG, Morel MA, Mauri L, Vranckx P, McFadden E, Lansky A, Hamon M, Krucoff MW, Serruys PW; Academic Research
Consortium. Clinical end points in coronary stent trials: a case for standardized definitions. Circulation. 2007;115:2344-51.

25. Mehran R, Rao SV, Bhatt DL, Gibson CM, Caixeta A, Eikelboom J, Kaul S, Wiviott SD, Menon V, Nikolsky E, Serebruany V, Valgimigli M, Vranckx P, Taggart D, Sabik JF, Cutlip DE, Krucoff MW, Ohman EM, Steg PG, White H. Standardized bleeding definitions for cardiovascular clinical trials: a consensus report from the Bleeding Academic Research Consortium. Circulation. 2011;123:2736-47.

26. Go AS, Hylek, EM, Chang Y, Phillips KA, Henault LE, Capra AM, Jensvold NG, Selby JV, Singer DE. Anticoagulation therapy for stroke prevention in atrial fibrillation. How well do randomized trials translate into clinical practice? JAMA. 2003;290:2685-92.

27. Manzano-Fernández S, Pastor FJ, Marín F, Cambronero F, Caro C, Pascual-Figal DA, Garrido IP, Pinar E, Valdés M, Lip GY. Increased major bleeding complications related to triple antithrombotic therapy usage in patients with atrial fibrillation undergoing percutaneous coronary artery stenting. Chest. 2008;134:559-67.

28. Lip GY, Frison L, Halperin JL, Lane DA. Comparative validation of a novel risk score for predicting bleeding risk in anticoagulated patient with atrial fibrillation. The HAS-BLED (Hypertension, Abnormal Renal/Liver Function, Stroke, Bleeding History Or Predisposition, Labile INR, Elderly, Drugs/Alcohol Concomitantly) score. J Am Coll Cardiol. 2011;57:173-80.

29. Go AS, Fang MC, Udaltsova N, Chang Y, Pomernacki NK, Borowsky L, Singer DE; ATRIA Study Investigators. Impact of proteinuria and glomerular filtration rate on risk of thromboembolism in atrial fibrillation: the anticoagulation and risk factors in atrial fibrillation (ATRIA) study. Circulation. 2009;119:1363-9.

30. Miyasaka Y, Barnes ME, Bailey KR, Cha SS, Gersh BJ, Seward JB, Tsang TS. Mortality trends in patients diagnosed with first atrial fibrillation. J Am Coll Cardiol. 2007;49:986-92.

31. Shlipak MG, Fried LF, Crump C, Bleyer AJ, Manolio TA, Tracy RP, Furberg CD, Psaty BM. Elevations of inflammatory and procoagulant biomarkers in elderly persons with renal insufficiency. Circulation. 2003;107:87-92.

32. McMahan DA, Smith DM, Carey MA, Zhou XH. Risk of major hemorrhage for outpatients treated with warfarin. $J$ Gen Intern Med. 1998;13:311-6.

33. Reineke H, Brand E, Mesters R, Schäbitz WR, Fisher M, Pavenstädt H, Breithardt G. Dilemmas in the management of atrial fibrillation in chronic kidney disease. J Am Soc Nephrol. 2009;20: 705-11.

34. Marinigh R, Lane DA, Lip GYH. Severe renal impairment and stroke prevention in atrial fibrillation. $\mathrm{J} \mathrm{Am}$ Coll Cardiol. 2011;57:1339-48. 